\title{
The influence of high fat diet on gut dysbiosis and myocardial function
}

\author{
Katarzyna Czarzasta, Piotr Dubinski, Dorota Sztechman, Liana Puhalska, Agnieszka Cudnoch-Jedrzejewska \\ Chair and Department of Experimental and Clinical Physiology, Laboratory of Center for Preclinical Research, Medical University of Warsaw, Warszawa, Poland
}

Correspondence to:

Katarzyna Czarzasta, MD, PhD,

Chair and Department of

Experimental and Clinical

Physiology, Laboratory of Center

for Preclinical Research,

Medical University of Warsaw,

Banacha 1B, 02-097 Warszawa,

phone: +48221166113,

e-mail:

katarzyna.czarzasta@wum.edu.pl

Copyright by the Author(s), 2022

DOI: 10.33963/KP.a2021.0143

Received:

May 31, 2021

Accepted:

October 22, 2021

Early publication date:

October 22, 2021

\section{INTRODUCTION}

Obesity is a chronic disease that is considered to be a global challenge according to the World Health Organization [1]. Experimental and clinical studies have shown that obesity caused by a high fat diet (HFD) is associated with the occurrence of myocardial fibrosis, atrial fibrillation, and left ventricular (LV) diastolic dysfunction (LVDD) [2, 3]. Recently, the influence of gut microbiota on the human body as well as on the activity of the cardiovascular system has been highlighted [4]. Obesity and an HFD lead to gut dysbiosis, which is defined as an imbalance of the composition of the microbiota. The occurrence of gut dysbiosis correlates with chronic systemic inflammation and, consequently, with an increased risk of cardiovascular diseases [5]. Gut dysbiosis caused by an HFD results in increased permeability of the gut epithelium and higher lipopolysaccharide (LPS) translocation into circulation, which contributes to metabolic endotoxemia [2]. LPS activates toll-like receptors (TLRs, such as TLR4 and TLR6), which, in turn, prompts the synthesis of various proinflammatory cytokines [6]. As a result, low-intensity systemic inflammation is induced, and it contributes to the onset and development of cardiovascular diseases [3,5]. However, the mechanism of the influence of gut dysbiosis caused by an HFD on myocardial function still needs to be elucidated. Therefore, this study aimed to investigate whether myocardial dysfunction under conditions of an HFD is related to gut dysbiosis.

\section{METHODS}

\section{Animals}

The study was conducted on 14 male Sprague Dawley rats (SPRD/Clzd). At four weeks of age, the rats were divided into two groups. The rats in the first group were on a normal fat diet (NFD, $n=7$, containing: $3.6 \%$ fat, $17.4 \%$ protein, $60 \%$ carbohydrates, $0.2 \%$ sodium, $2864 \mathrm{kcal} / \mathrm{kg}$; Labofeed B, Kcynia, Poland) and had mean body weight [b.w.] 335 g. The rats in the second group were on a high fat diet (HFD, $n=7$; containing: $31 \%$ fat, $17.1 \%$ protein, $35.5 \%$ carbohydrates, $0.18 \%$ sodium, $3842 \mathrm{kcal} / \mathrm{kg}$; Labofeed B, Kcynia, Poland) and had mean body weight: $332 \mathrm{~g}$.

The study was approved by the Local Animal Research Ethics Committee in Warsaw (226/2016).

Then the rats were subjected to the following procedures:

\section{Fecal microbiota analysis}

Feces for microbiota analysis were collected from randomly selected 12-week-old rats on a NFD ( $\mathrm{n}=3$; mean b.w.: $340 \mathrm{~g})$ and an HFD $(\mathrm{n}=3$; mean b.w.: $348 \mathrm{~g})$. A fecal microbiota analysis was carried out at a veterinary laboratory (ALAB Weterynaria, Warszawa, Poland). The quantitative evaluation of fecal bacteria was performed using the serial dilution method. $0.1 \mathrm{ml}$ of the given dilution was placed in duplicate on agar plates, which were incubated for 48 hours in aerobic or anaerobic conditions at a temperature of $37^{\circ} \mathrm{C}$. 


\section{Echocardiography analysis}

The same rats on an NFD $(n=3)$ and an HFD $(n=3)$ from which feces were collected for microbiological analysis were subjected to the echocardiography study. Baseline echocardiography was performed under general anesthesia (Ketamine $10 \mathrm{mg} / 100 \mathrm{~g}$ b.w., intraperitoneal with Xylazine $1 \mathrm{mg} / 100 \mathrm{~g}$ b.w., intraperitoneal), and a Vivid i machine (Biosense Webster Inc.) equipped with a $12 \mathrm{MHz}$ electronic transducer was used. Parameters related to the systolic and diastolic functions of the LV, the mitral annular plane systolic excursion, the tricuspid annular plane systolic excursion, the LV outflow tract velocity time integral, and the heart rate were analyzed.

Immediately after the echocardiography test, all of the rats on an NFD $(n=7)$ and an HFD $(n=7)$ were euthanized to enable plasma and LV tissue collection for the following biochemical analyses:

\section{Real-time PCR (RT-PCR) analysis}

Multiplex RT-PCR analysis was conducted in accordance with the Applied Biosystems protocol using the TaqMan RNA-to-Ct ${ }^{\text {TM }}$ 1-Step Kit, a primer for the rat TLR4 receptor (Rn00569848_m1; Applied Biosystems), a primer for the rat TLR6 receptor (Rn02121288_s1; Applied Biosystems), and a housekeeping gene primer for the rat GADPH (Rn01775763_g1).

\section{Western Blot analysis}

Western Blot analysis was performed according to the protocol described earlier [7]. We used the following antibodies: a primary mouse monoclonal antibody against TLR4 (1:200 dilution, sc-293072; Santa Cruz Biotechnology, Dallas, TX, USA), a primary mouse monoclonal antibody against TLR6 (1:1000 dilution, ab228424; Abcam, Cambridge, UK), a primary mouse monoclonal antibody anti- $\beta$ Actin (1:1000 dilution, ab8226; Abcam), a secondary antibody: goat anti-mouse conjugated to Horseradish Peroxidase (HRP) (1:2000 dilution, ab205719; Abcam). TTBS solution (0.5\% Tween 20 in TBS; Bio-Rad, Hercules, CA, USA) containing $5 \%$ skim milk was used as a blocking factor. TLR4 and TLR6 protein levels were standardized by $\beta$-actin.

\section{ELISA analysis}

Plasma LPS concentrations were determined by enzyme-linked immunosorbent assay (ELISA) following the manufacturer's instructions (Rat Lipopolysaccharides [LPS] ELISA Kit; MBS268498; MyBioSource Inc., San Diego, (A, USA)

\section{Statistical analysis}

Statistical analysis was performed using the Statistica software version 13 . The obtained data were analyzed with the Student's t-test. The differences were considered statistically significant if $P<0.05$. The results were reported as the mean and the standard errors.

\section{RESULTS}

\section{Gut microbiota composition}

In the fecal cultures of the NFD rats as well as of the HFD rats we observed (measured as colony-forming units per gram - cfu/g) in the phylum Proteobacteria: Escherichia coli $\left(\mathrm{NFD}=2 \times 10^{7}\left[1 \times 10^{7}\right] \mathrm{cfu} / \mathrm{g}\right.$ vs. HFD $\left.=1 \times 10^{7}\left[3 \times 10^{6}\right] \mathrm{cfu} / \mathrm{g}\right)$; phylum Firmicutes: Enterococcus spp. $\left(\mathrm{NFD}=7 \times 10^{7}\left[4 \times 10^{7}\right]\right.$ $\mathrm{cfu} / \mathrm{g}$ vs. HFD $\left.=2 \times 10^{7}\left[6 \times 10^{6}\right] \mathrm{cfu} / \mathrm{g}\right)$, Lactobacillus spp. $\left(\mathrm{NFD}=9 \times 10^{9}\left[1 \times 10^{9}\right] \mathrm{cfu} / \mathrm{g}\right.$ vs HFD $=1 \times 10^{9}\left[3 \times 10^{8}\right]$ $\mathrm{cfu} / \mathrm{g})$, Clostridium spp. (NFD $=7 \times 10^{4}\left[1 \times 10^{3}\right] \mathrm{cfu} / \mathrm{g}$ vs. HFD $\left.=6 \times 10^{3}\left[1 \times 10^{3}\right] \mathrm{cfu} / \mathrm{g}\right)$; phylum Bacteroidetes: Bacteroides spp. (NFD $=3 \times 10^{6}\left[1 \times 10^{6}\right] \mathrm{cfu} / \mathrm{g}$ vs. $\left.\mathrm{HFD}=5 \times 10^{6}\left[3 \times 10^{6}\right] \mathrm{cfu} / \mathrm{g}\right)$; phylum Actinobacteria: Bifidobacterium spp. (NFD $=1 \times 10^{9}\left[3 \times 10^{8}\right] \mathrm{cfu} / \mathrm{g}$ vs. $\left.\mathrm{HFD}=1 \times 10^{9}\left[3 \times 10^{8}\right] \mathrm{cfu} / \mathrm{g}\right)$. However, there were no significant differences in the composition of fecal cultures between the NFD and HFD groups.

\section{Echocardiography analysis}

Echocardiography showed mild left atrium (LA) hypertrophy in the HFD rats $(5.69[0.22] \mathrm{mm})$ compared to the NFD rats $(4.63[0.11] \mathrm{mm} ; P<0.05)$. There was also a decrease in the è-wave velocity in the HFD rats $(0.05[0.003] \mathrm{m} / \mathrm{s})$ in comparison with the NFD rats $(0.06[0.001] \mathrm{m} / \mathrm{s} ; P<0.05)$, which may indicate LVDD. Nevertheless, the other echocardiographic parameters, including LV systolic function, did not differ between the HFD rats and the NFD rats.

\section{mRNA expression and protein levels of TLR4 and TLR6 $m R$ RNA in the left ventricular}

TLR4 $(P<0.001$; Figure $1 A)$ and TLR $6(P<0.001$; Figure 1B) mRNA expression, as well as TLR4 protein level $(P<0.001$; Figure 1C), were higher in the LV in the HFD rats compared with the NFD rats. On the other hand, there were no differences in the TLR6 protein level in the LV between both groups of rats $(P=0.87$; Figure 1D).

\section{Plasma LPS level}

There were no differences in the plasma LPS level between the NFD rats $(6.98[0.67] \mathrm{ng} / \mathrm{ml})$ and the HFD rats $(9.04[0.82]$ $\mathrm{ng} / \mathrm{ml} ; P=0.078)$.

\section{DISCUSSION}

The main observation emerging from the present study is that HFD may contribute to the development of LA hypertrophy and LVDD via TLRs.

Microbiological analysis showed no differences in fecal microbiota composition between rats on HFD and NFD. However, available studies demonstrated that, in obese patients, a reduction in the number of bacteria from the phylum Firmicutes and an increase in the number of bacteria from the phylum Bacteroidetes were observed [8]. It was also shown that LPS is one of the metabolites of bacteria of the phylum Bacteroidetes [6]. The primary point of LPS 


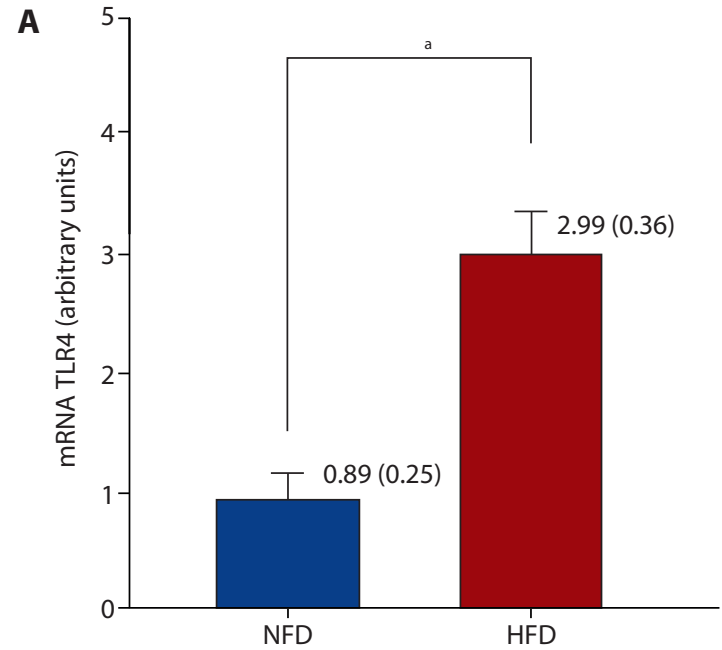

\section{C}

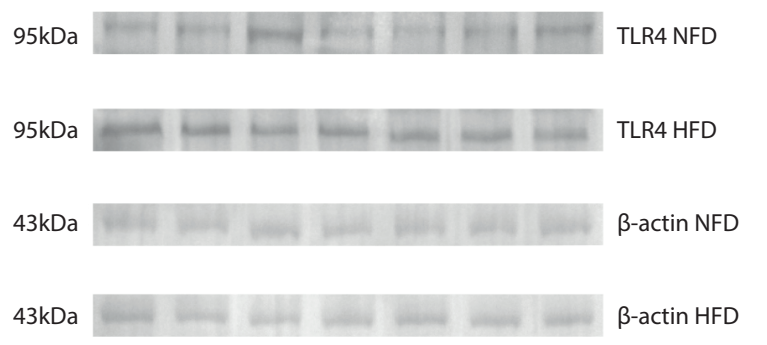

$\mathbf{E}$

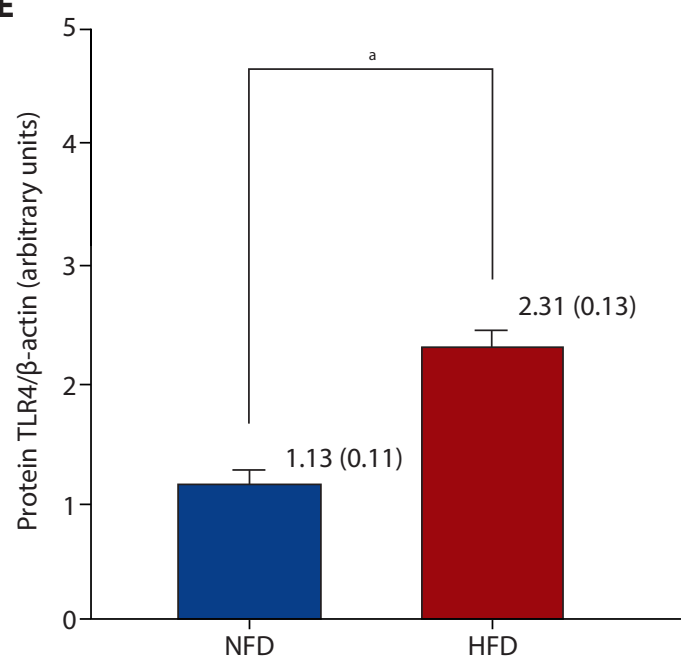

B

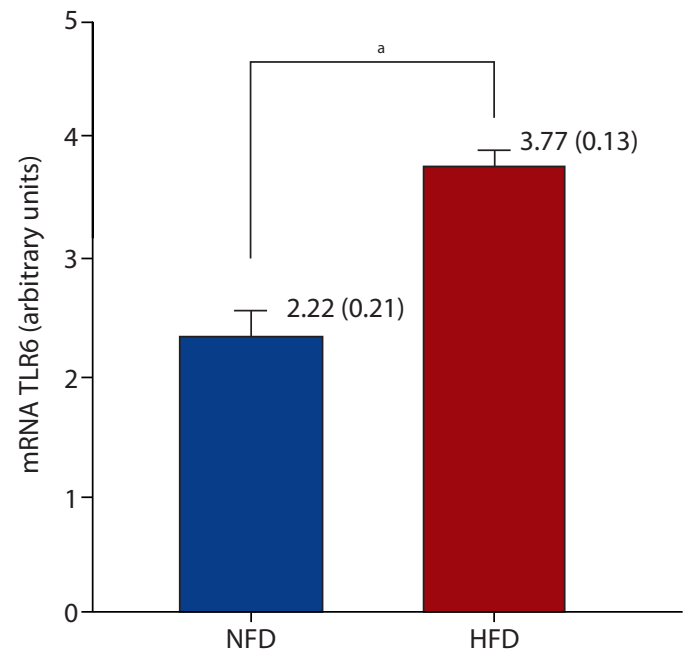

D

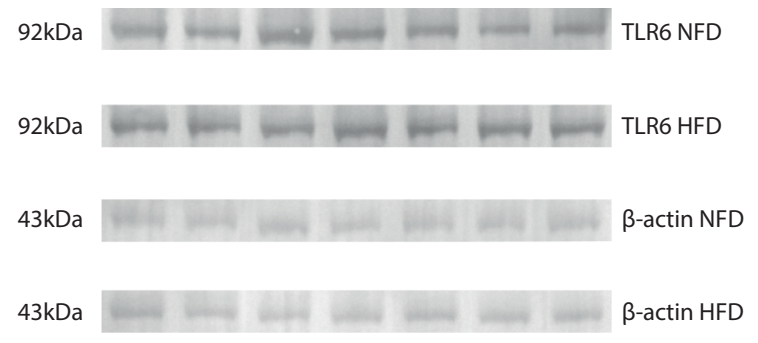

$\mathbf{F}$

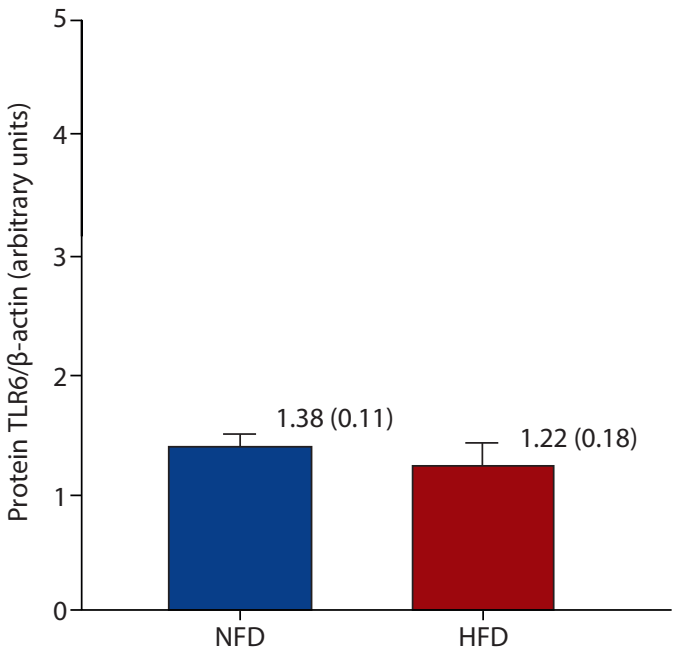

Figure 1. Expression of toll-like receptor type 4 (TLR4) mRNA (A) and protein (C, E), and toll-like receptor type 6 (TLR6) mRNA (B) and protein $(\mathbf{D}, \mathbf{F})$ in the left ventricle tissue in rats on a normal fat diet (NFD) and rats on a high fat diet (HFD). Means (SE) are shown; ${ }^{a} P<0.001$

uptake is TLR receptors [6]. In the present study, an increase in the expression of TLR4 and TLR6 mRNA and TLR4 protein levels in the LV of HFD rats was demonstrated. The results of the previous studies confirm the association of excessive fat consumption and obesity with the stimulation of TLR receptors, inducing generalized low-grade chronic inflammation, which increases cardiovascular risk [9]. In our previous study, we have shown a link between the development of systemic inflammation accompanying obesity and an increase in myocardial fibrosis, which may affect heart function [3]. Similarly, in this study, we have demonstrated that HFD contributes to mild LA hypertrophy and the development of LVDD. Clinical studies showed that obese patients were more likely to have an enlarged LA diameter, which was strongly associated with atrial fibrillation [10]. Moreover, it was found that a high body mass index is an independent risk factor for the development of atrial fibrillation [10]. 
In conclusion, the present study indicates that myocardial dysfunction in rats on an HFD may be related to TLR receptors.

\section{Study limitations}

Evaluation of the fecal microbiota composition and echocardiography was performed on a small number of rats (NFD = 3, HFD = 3), which affected the statistical power of the study. The fecal microbiota composition was assessed using a traditional microbiological method.

\section{Article information}

Acknowledgments: This study was financially supported by statutory funds from the Medical University of Warsaw (1MA/N/2020).

Conflict of interest: None declared.

Open access: This article is available in open access under Creative Common Attribution-Non-Commercial-No Derivatives 4.0 International (CC BY-NC-ND 4.0) license, allowing to download articles and share them with others as long as they credit the authors and the publisher, but without permission to change them in any way or use them commercially. For commercial use, please contact the journal office at kardiologiapolska@ptkardio.pl.

\section{REFERENCES}

1. Yumuk V, Tsigos C, Fried M, et al. Obesity Management Task Force of the European Association for the Study of Obesity. European guidelines for obesity management in adults. Obes Facts. 2015; 8(6): 402-424, doi: 10.1159/000442721, indexed in Pubmed: 26641646.

2. Csige I, Ujvárosy D, Szabó Z, et al. The impact of obesity on the cardiovascular system. J Diabetes Res. 2018; 2018: 3407306, doi: 10.1155/2018/3407306, indexed in Pubmed: 30525052.

3. Czarzasta K, Koperski L, Segiet A, et al. The effects of a high-fat diet on left ventricular fibrosis. Kardiol Pol. 2018; 76(4): 802-804, doi: 10.5603/KP.2018.0080, indexed in Pubmed: 29652426.

4. Katsimichas T, Antonopoulos AS, Katsimichas A, et al. The intestinal microbiota and cardiovascular disease. Cardiovasc Res. 2019; 115(10): 1471-1486, doi: 10.1093/cvr/cvz135, indexed in Pubmed: 31161201

5. Duan $Y$, Zeng $L$, Zheng $C$, et al. Inflammatory links between high fat diets and diseases. Front Immunol. 2018; 9: 2649, doi: 10.3389/fimmu.2018.02649, indexed in Pubmed: 30483273.

6. Kell DB, Pretorius E. On the translocation of bacteria and their lipopolysaccharides between blood and peripheral locations in chronic, inflammatory diseases: the central roles of LPS and LPS-induced cell death. Integr Biol (Camb). 2015; 7(11): 1339-1377, doi: 10.1039/c5ib00158g, indexed in Pubmed: 26345428.

7. Czarzasta K, Wojno O, Zera T, et al. The influence of post-infarct heart failure and high fat diet on the expression of apelin APJ and vasopressin V1a and V1b receptors. Neuropeptides. 2019; 78: 101975, doi: 10.1016/j. npep.2019.101975, indexed in Pubmed: 31645268.

8. Ley RE, Turnbaugh PJ, Klein S, et al. Microbial ecology: human gut microbes associated with obesity. Nature. 2006; 444(7122): 1022-1023, doi: 10.1038/4441022a, indexed in Pubmed: 17183309.

9. Suzuki K. Chronic inflammation as an immunological abnormality and effectiveness of exercise. Biomolecules. 2019; 9(6): 223, doi: 10.3390/biom9060223, indexed in Pubmed: 31181700.

10. Panchal G, Mahmood M, Lip GYH. Revisiting the risks of incident atrial fibrillation: a narrative review. Part 2. Kardiol Pol. 2019; 77(5): 515-524, doi: 10.33963/KP.14846, indexed in Pubmed: 31125027. 